\title{
Evolução do pensamento, raciocínio e desempenho em alunos do ensino superior
}

\author{
Emília da Conceição Figueiredo Martins \\ Instituto Politécnico de Viseu, Portugal \\ Joaquim Armando Gomes Ferreira \\ Universidade de Coimbra, Portugal
}

\begin{abstract}
Resumo
O estudo aqui apresentado insere-se no contexto do crescente interesse sobre o impacto do ensino superior no desenvolvimento cognitivo do estudante, despoletado não só pela psicologia do desenvolvimento, mas também pela mudança de paradigma de formação no ensino superior, assente nos desafios da globalização e consolidada na Declaração de Bolonha. Nesse sentido, acompanhámos uma amostra de alunos do ensino superior politécnico, ao longo de três anos lectivos consecutivos, com avaliações do pensamento (Perry, 1970), raciocínio (conteúdos numérico e verbal) e desempenho académico (média de classificações e unidades de crédito realizadas). Os resultados remetem para uma evolução favorável do raciocínio, o mesmo não acontecendo ao pensamento, em que se constatam descidas nos níveis de relativismo e compromisso atingidos, não obstante a diminuição do pensamento dualista significar melhorias cognitivas neste domínio. Daqui decorrem implicações que exigem discussão/reflexão sobre modelos e processos de ensino/aprendizagem, no âmbito da avaliação interna de cada estabelecimento.
\end{abstract}

Palavras-chave

Ensino superior; Desenvolvimento cognitivo; Desempenho

\section{Introdução}

O estudo do impacto do ensino superior no desenvolvimento do estudante tem vindo, progressivamente, a ser alvo das atenções de investigadores estrangeiros e nacionais. A influência decisiva da psicologia do 
desenvolvimento coextensivo à duração da vida (life span), aliada à proximidade física de investigadores e amostra (frequentemente, os primeiros são docentes no ensino superior), bem como a mudança de paradigma formativo do ensino superior (com a valorização de competências genéricas transferíveis, para além da formação profissional), constituem um pilar sólido de sustentação daquele interesse.

Todavia, é recomendável alguma prudência na abordagem do desenvolvimento em contexto de ensino superior, sobretudo em estudos num curto prazo de tempo, sendo necessário distinguir os termos mudanças e desenvolvimento, não obstante serem, frequentemente, utilizados como sinónimos. Assim, enquanto mudança se refere às alterações qualitativas ou quantitativas nas características cognitivas ou afectivas dos alunos e não implica direccionalidade, desenvolvimento refere-se a padrões ou processos intra-individuais e implica ordem e direccionalidade hierárquica ou evolutiva (Pascarella \& Terenzini, 2005). Desenvolvimento é, neste contexto, um processo de reestruturação interna em direcção a um nível de complexidade superior, que se manifesta por mudanças individuais, mas que dificilmente ocorrem durante um período de tempo curto. Com efeito, as mudanças observadas, no comportamento dos estudantes, podem corresponder a processos desenvolvimentais, mas também estar relacionadas com aspectos inerentes ao processo de socialização. Mais do que saber se estamos perante mudança ou desenvolvimento, não descurando que o impacto de um mesmo contexto está condicionado pelas características individuais (Pascarella \& Terenzini, 2005), interessa conhecer os factores que podem conduzir a ambos, como ainda identificar as alterações produzidas e o sentido das mesmas.

Em termos metodológicos, o panorama tem sido dominado pelas metodologias quantitativas e os designs transversais que, por razões óbvias, são maioritários. Por outro lado, o contexto norte-americano foi berço e ainda hoje lidera os trabalhos neste domínio. Aliás, é este o testemunho dado pela literatura, incluindo o trabalho desenvolvido por dois autores de referência, Ernest Pascarella e Patrick Terenzini (professores na University of lowa e The Pennsylvania State University, respectivamente), não só como investigadores, mas ainda na compilação e síntese da investigação realizada durante mais de três décadas (desde 1970), em contexto americano, contando com a 
publicação de duas obras de referência. How College Affects Students: A third decade of research (2005) surge no seguimento de uma primeira, publicada em 1991, How College Affects Students: Two decades of research ${ }^{1}$. Para os autores, as diferenças entre as duas publicações incidem, fundamentalmente, em cinco dimensões: (1) alteração da população de estudo (para além do estudante tradicional, começa o interesse pela diversidade dentro desta população); (2) alteração, por diversificação, do tipo de instituição considerada; (3) alteração na concepção de aprendizagem, desenvolvimento (envolve aquisição, mas também auto-construção) e metodologias de ensino, sobre as quais a investigação teve que incidir; (4) alteração de políticas educativas e características das vivências no seio das instituições (os avanços sociais e tecnológicos obrigaram a novas linhas de investigação); (5) alteração nos paradigmas de investigação (tónica positivista tende a encaminhar-se para abordagens qualitativas).

Em termos de resultados, constatam-se evidências claras de mudanças positivas e duradouras (permanecem para além do período de frequência deste nível de ensino), causadas pelo impacto do ensino superior (não atribuíveis a outras influências), a vários níveis e dimensões do desenvolvimento, que dependem do tipo de instituição frequentada e da diversidade de experiências proporcionadas, bem como das características individuais dos alunos.

No contexto português, tem sido crescente o interesse por estudos sobre o desenvolvimento do estudante do ensino superior, iniciado, praticamente, na década de 90 do século XX (Bastos, 1993, 1998; Bastos, Faria, Silva, Carvalho, \& Gonçalves, 2003; Bastos, Faria, Soares, Ferreira, Medeiros, \& Silva, 2005; Faria \& Bastos, 2005; Ferreira, 1991; Ferreira \& Bastos, 1995; Ferreira \& Hood, 1990; Martins, 2005, 2007; Medeiros et al., 2002; Pereira \& Medeiros, 2005; Pinheiro, 2003; Pires, 2001; Ribeiro, 1996), bem como por aqueles que se preocupam com o processo de transição e adaptação a este nível de ensino (Almeida, Soares, \& Ferreira, 1999; Almeida, Santos, Dias, Botelho \& Ramalho, 1998; Diniz, 2001; Ferreira, 2003; Ferreira \& Hood, 1990; Gonçalves \& Cruz, 1998; Leitão \& Paixão, 1999; Pinheiro, 2003; Pinheiro \& Ferreira, 2002; Silva, 2003; Soares, 1998). O presente estudo elegeu o desenvolvimento cognitivo na dupla acepção da construção do pensamento e da realização cognitiva, ou seja, associámos constructos de 
216 Emília da Conceição Figueiredo Martins \& Joaquim Armando Gomes Ferreira

desenvolvimento e desempenho cognitivo, considerando, no primeiro, a teoria de desenvolvimento intelectual e ético de William Perry (1970) e, no segundo, o raciocínio numérico e verbal enquadrados pelas aptidões intelectuais. Paralelamente, procurámos verificar se o desempenho académico evoluía no mesmo sentido, ou seja, se o perfil de alterações ocorridas na cognição e desempenho percorria um traçado semelhante. Assim, acompanhámos um grupo de alunos do ensino superior ao longo de três avaliações consecutivas, com intervalo de um ano. Não obstante a quase obrigatoriedade de uma amostra mais reduzida, a par das consequências da mortalidade da mesma, pretendeu-se eliminar os efeitos da coorte, numa abordagem longitudinal que é, claramente, minoritária, no panorama investigativo português.

\section{Contributos da investigação sobre o desenvolvimento e realização cognitiva no ensino superior}

$O$ interesse crescente pelo impacto do ensino superior no desenvolvimento do pensamento do jovem adulto e/ou adulto emergente, nas últimas décadas, tem incidido sobre constructos distintos, enquadrados sob a designação de pós formal (ou seja, para além do formal piagetiano), cujas características aglutinadoras são, de acordo com Kitchener e King (1981) e Kramer (1983), a tomada de consciência do carácter relativista do conhecimento, a aceitação da contradição e a integração de subsistemas em totalidades abrangentes. De entre a diversidade de perspectivas de abordagem, seleccionámos o modelo teórico de Perry (1970) sobre o desenvolvimento cognitivo e ético do estudante do ensino superior, que se insere num referencial cognitivo-estruturalista. Nesta perspectiva, o desenvolvimento intelectual é explicado a partir da forma como os indivíduos pensam e atribuem significado às experiências por que vão passando, tendo por base três níveis de pensamento. Partindo de um nível elementar (dualismo), que opõe o certo ao errado, admite-se, progressivamente, o carácter relativo do conhecimento (relativismo), até que se assume uma posição de comprometimento com o sistema de valores que foi sendo construído (compromisso no relativismo). Ainda que começando por fazê-lo numa área em particular, que se generaliza através de responsabilidades crescentes, o indivíduo vai expressando o seu estilo de vida e identidade. Segundo o autor, as experiências de escolarização apresentam-se como 
positivas para o desenvolvimento (diminuição progressiva do dualismo e consequente aumento do relativismo e compromisso), não se excluindo a possibilidade de paragens temporárias (temporizing) ou regressões (retreat) enquanto mecanismos de defesa a pressões sentidas como demasiado fortes.

Genericamente, e de acordo com Hofer e Pintrich (1997), distinguemse três grandes linhas ou eixos de investigação, cujos resultados remetem para a confirmação do movimento descrito por Perry, ou seja, para uma melhoria das formas de pensar com a frequência do ensino superior: (1) uma que procura criar e testar modelos cognitivo-estruturais, e que foi iniciada por Perry; (2) uma segunda que assenta na pesquisa sobre o julgamento reflexivo, da responsabilidade de King e Kitchener; e, finalmente, (3) uma terceira voltada para a epistemologia pessoal, que associamos a BaxterMagolda.

O principal trabalho de pesquisa sobre o julgamento reflexivo foi, sem dúvida, o desenvolvido por King e Kitchener e colaboradores, durante mais de uma década, envolvendo estudos longitudinais e transversais e sintetizado, em 1994, na obra Developing Reflective Judgment, de onde se destaca uma pesquisa entre 1977 e 1987, com quatro avaliações (duas nos dois primeiros anos e as restantes de quatro em quatro anos) e com sujeitos de idades compreendidas entre 16 e 28 anos na primeira avaliação (20 estudantes do ensino secundário, 40 do primeiro ano do ensino superior e 20 a frequentar programas de doutoramento). Os alunos de níveis de escolaridade superiores apresentaram melhores performances do que os de nível inferior; em todos os grupos se revelaram alterações positivas ao longo do tempo; a maior progressão aconteceu nos níveis mais baixos, sendo que os alunos de doutoramento apresentaram alguma estabilidade da penúltima para a última investigação; não houve casos de declínio e a evolução foi lenta e segura. Numa revisão de trabalhos, de outros autores, longitudinais e transversais, e pesquisas que compararam sujeitos com e sem frequência de ensino superior, as autoras verificaram que, não obstante as características distintas nas amostras e intervalo de tempo entre as avaliações, ou se regista estabilidade, ou se verifica um aumento na complexidade do pensamento, sendo que as mudanças significativas acontecem nos períodos inter-avaliações mais longos. Também os alunos que prosseguiram estudos se distinguiram 
significativamente dos restantes. Para além da pesquisa de King e Kitchener, são múltiplas as referências da literatura a trabalhos que incidem sobre 0 impacto da frequência do ensino superior no julgamento reflexivo (Kitchener \& Wood, 1987; Mines, King, Hood, \& Wood, 1990; Perkins, 1985; Pascarella \& Terenzini, 2005; Schmidt, 1985; Whitla, 1978; Wood, 1997).

Os trabalhos de Perry e Baxter-Magolda entrecruzam-se e os resultados são, igualmente, condizentes com um efeito positivo da exposição ao ensino superior, tal como é evidenciado por Pascarella e Terenzini (2005), tanto nos estudos de carácter longitudinal como transversal (Hart, Richards, \& Mentkowski, 1995; Moore, 1991; Pearson \& Rodgers, 1998). Muitos outros trabalhos concluíram de forma semelhante, na realidade portuguesa (Bastos, 1998; Bastos et al., 2005; Bastos, Faria, Silva, Carvalho \& Gonçalves, 2003; Faria \& Bastos, 2005; Martins, 2005; Medeiros et al., 2002; Pereira \& Medeiros, 2005; Pires, 2001) ou outra (Baxter-Magolda \& Porterfield, 1985; Blacke, 1976; Meyer, 1977; Moore, 1989). Dos trabalhos realizados em Portugal, sobressaem como aspectos principais: (1) diferença quantitativa desfavorável relativamente à investigação desenvolvida noutras realidades; (2) designs maioritariamente transversais; (3) resultados genéricos de evolução positiva dos aspectos de natureza cognitiva durante o ensino superior, ainda que, por vezes, sem significado estatístico; (4) estudos baseados no modelo de Perry põem em evidência um padrão onde predominam o relativismo e compromisso, cuja evolução começa por ganhos nos níveis inferiores (descida no dualismo) estendendo-se, progressivamente, aos níveis superiores; e (5) influência de outras variáveis de contexto, sobretudo a área de estudos ou formação, nos resultados obtidos. No entanto, há trabalhos em que, ou não se registam alterações significativas, ou se constatam descidas, ou valores inferiores, nos alunos de ano curricular mais avançado (Bastos et al., 2003; Martins, 2007; Pereira \& Medeiros, 2005). Com efeito, Bastos et al. (2003), na segunda avaliação de alunos finalistas de Educação de Infância (no final do ano e, consequentemente, do curso), encontraram declínio no relativismo da Carreira, justificado pela pressão da aproximação do mercado de trabalho. Também Pereira e Medeiros (2005) verificaram valores de dualismo inferiores, à medida que se comparam alunos de Enfermagem do $1^{\circ}$ até ao $3^{\circ}$ anos, que voltam a subir nos alunos finalistas ( $4^{\circ}$ ano). Não obstante os autores explicarem estes resultados por estágios 
profissionais mais intensivos, que dependem mais da lógica inerente à cultura institucional do local de estágio, também estes alunos estão próximos de ingressar no mercado de trabalho. Martins (2007), num design transversal com alunos do ensino politécnico (áreas de saúde e educação), constatou valores inferiores no pensamento relativista e no compromisso, em alunos de $2^{\circ}$ e $3^{\circ}$ anos, relativamente aos do $1^{\circ}$, ainda que se verificasse uma evolução positiva no dualismo, nos alunos de nível de escolaridade superior. Resultados diferentes (melhoria nos três níveis de pensamento) com uma subamostra do ensino universitário levaram a autora a colocar a hipótese de atribuir as diferenças aos modelos de formação, metodologias utilizadas e vivências potenciadas pelos dois subsistemas de ensino superior.

No que respeita à realização cognitiva, a estabilidade das aptidões defendida pela perspectiva psicométrica não significa imutabilidade, mas apenas falar de um desempenho positivamente correlacionado ao longo do tempo. É assim que o desenvolvimento das aptidões se tem vindo a associar a alterações em três vertentes: (1) relativa aos padrões de desenvolvimento (aumento, manutenção e declínio ao longo do ciclo de vida); (2) relativa à estrutura de aptidões (alteração nas correlações entre os testes de aptidão em função da idade); e (3) relativa ao efeito de experiências intencionalizadas de aprendizagem (Ribeiro, 1996). Enquanto experiência de escolarização, a influência do ensino superior no desenvolvimento das aptidões pode ser enquadrada no contexto da última vertente. Se durante muito tempo se olhou para esta relação em termos de capacidade preditiva das aptidões relativamente ao desempenho académico ou escolar, as atenções começaram, progressivamente, a voltar-se para relações de reciprocidade (Snow, 1994). Segundo Ribeiro (1996), a influência da escolarização no desenvolvimento das aptidões é explicada, na literatura, quer directamente, através dos conhecimentos escolares que, simultaneamente, são respostas a itens dos testes de inteligência, quer indirectamente, pelos processos de aprendizagem implicados em actividades escolares que têm influência em processos e estratégias cognitivas envolvidas na resolução dos testes de inteligência.

Hoje contamos já com um leque muito vasto de estudos neste domínio, ainda que, em Portugal, incidam, maioritariamente, nos contextos de escolarização anteriores ao ensino superior. Os resultados evidenciam um 
impacto positivo, com os alunos a apresentarem subidas nas performances à medida que progridem na escolaridade pós secundária (Bowen, 1977; Cahan \& Cohen, 1989; Flowers \& Pascarella, 1999; Myerson, Rank, Raines, \& Schnitzler, 1998; Osterlind, 1996, 1997; Pascarella \& Terenzini, 1991, 2005; Ribeiro, 1996; Thorndike \& Andrieu-Parker, 1992; Underwood, Maes, Alstadt, \& Boivin, 1996). Por outro lado, ressalta uma relação estreita entre o desenvolvimento das aptidões e a área de estudos frequentada, assente na proximidade de conteúdos (Anaya, 1996; Angoff \& Johnson, 1990; Astin, 1993; Pinto, 2003; Ratcliff, 1993; Ratcliff \& Jones, 1993; Ratcliff \& Yaeger, 1994). Também, as aptidões verbais e numéricas surgem como as mais correlacionadas com os resultados escolares, para além dos melhores desempenhos verbais relativamente aos numéricos (Almeida 1986; Almeida, 2004; Almeida \& Campos, 1986; Barros, Fernandes, Almeida, \& Primi, 1999; Ribeiro, 1996). No que respeita à influência de outras variáveis na forma como evoluem as performances nas aptidões, há resultados diversos, que remetem para efeitos de género, classe social, área de estudos, instituição frequentada, envolvimento académico, etc. (Almeida, 1988; Anaya, 1999; Flowers, 2000; Flowers et al., 1999; Hagedorn, Siadat, Nora, \& Pascarella, 1997; Li, Hideki, \& Mervin, 1996; Pascarella \& Terenzini, 1991, 2005; Pinto, 2003; Ransdell, Hawkins, \& Adams, 2001; Ribeiro, 1996).

O estudo realizado pretende ser um contributo para o estudo da evolução do pensamento e da realização cognitiva em contexto de ensino superior português, colhendo os benefícios do recurso a um design longitudinal, com três avaliações anuais.

\section{Problema e hipóteses}

A revisão da literatura, para além de elencar o contributo de um apreciável conjunto de variáveis, evidencia o carácter multidimensional desta problemática e permitiu-nos recortar o seguinte problema:

Em que sentido, direcção e com que magnitude evolui o desenvolvimento do pensamento e raciocínio, bem como o desempenho escolar, dos alunos de três cursos do Instituto Politécnico de Viseu, ao longo de três anos de frequência do ensino superior? 
Procurámos dar resposta a seis hipóteses de estudo, emergentes da pertinência revelada em outros estudos ou da própria ausência de estudos:

Hipótese 1 (H1) - Há mudanças significativas nas dimensões do raciocínio numérico e verbal, avaliadas pela PARC, nos três momentos temporais considerados (T1, T2 e T3).

Hipótese $2(\mathrm{H} 2)$ - Há estabilidade nas mudanças ocorridas no raciocínio numérico e verbal ao longo dos três momentos temporais.

Hipótese $3(\mathrm{H} 3)$ - Há mudanças significativas nos níveis do pensamento, avaliados pelo IDCP, nos três momentos temporais considerados (T1, T2 e T3).

Hipótese $4(\mathrm{H} 4)$ - Há estabilidade nas mudanças ocorridas no pensamento, ao longo dos três momentos temporais.

Hipótese 5 (H5) - Há mudanças significativas nas médias de classificação, nos três momentos temporais considerados (T1, T2 e T3).

Hipótese $6(\mathrm{H} 6)$ - Há estabilidade nas mudanças ocorridas nas médias de classificação, ao longo dos três momentos temporais.

\section{Metodologia}

\subsection{Sujeitos}

A amostra, de conveniência (alunos que assistiram às aulas em que foram recolhidos os dados), é constituída por 210 alunos, e corresponde a $79,5 \%$ da população admitida, em 2003/2004, aos cursos de Enfermagem (100\%), Professores do $1^{\circ}$ Ciclo do Ensino Básico (72,2\%) e Educadores de Infância (50\%), no Instituto Politécnico de Viseu. Tendo em conta a natureza longitudinal do estudo, com três momentos de avaliação, registou-se uma mortalidade de $10 \%$ da amostra do primeiro (T1) para o segundo momento (T2), e de $42,9 \%$ do segundo para o terceiro (T3), o que corresponde a uma perda total de $48.57 \%$ de T1 para T3. Salienta-se que a maior perda pertence aos alunos de Enfermagem (de T2 para T3), devido a exclusão provocada por impossibilidade temporal de acompanhar uma turma admitida, apenas, em Março de 2004, até Março de 2006 (T3).

Como podemos constatar (Quadro 1), trata-se de uma amostra maioritariamente feminina, sendo isomorfa em relação à população abrangida 
(cursos de enfermagem e formação de professores). Os participantes distribuem-se, fundamentalmente, pelos níveis sócio-económicos baixo $(75,7 \%)$ e médio $(23,3 \%)$, sendo de desprezar $1 \%$ de nível elevado 2 .

Quadro 1 - Distribuição dos sujeitos por estabelecimento e curso, em função do género (frequências e \%), idade (média, desvio padrão e amplitude) e momento de avaliação

\begin{tabular}{|c|c|c|c|c|c|c|c|c|c|c|c|c|}
\hline \multirow[t]{3}{*}{ Curso } & \multicolumn{6}{|c|}{ Género } & \multirow{2}{*}{\multicolumn{3}{|c|}{ Idade }} & \multirow{2}{*}{\multicolumn{3}{|c|}{ N/Momento }} \\
\hline & \multicolumn{2}{|c|}{$\mathrm{F}$} & \multicolumn{2}{|c|}{$M$} & \multicolumn{2}{|c|}{ Total } & & & & & & \\
\hline & $\mathrm{N}$ & $\%$ & $\mathrm{~N}$ & $\%$ & $\mathrm{~N}$ & $\%$ & $\mathrm{~N}$ & $M$ & DP & $\mathrm{T} 1$ & $\mathrm{~T} 2$ & $\mathrm{~T} 3$ \\
\hline \multicolumn{13}{|l|}{ ESEV } \\
\hline $1^{\circ}$ Ciclo & 47 & 904 & 5 & 96 & 52 & $24 \pi 6$ & 51 & 19.39 & 1.76 & 52 & 40 & 35 \\
\hline Ed. Infância & 34 & 944 & 2 & 56 & 36 & 17.14 & 36 & 19.17 & 1.34 & 36 & 30 & 28 \\
\hline \multicolumn{13}{|l|}{ ESENF } \\
\hline Enferm. & 96 & 787 & 26 & 213 & 122 & 58.10 & 99 & 18.77 & 1.14 & 122 & 119 & 45 \\
\hline Total & 177 & 843 & 33 & 15.7 & 210 & 100 & 106 & 1902 & 150 & 210 & 189 & 108 \\
\hline
\end{tabular}

No que respeita às variáveis académicas, destacam-se, nas classificações de acesso ao ensino superior ${ }^{3}$, resultados superiores da frequência do ensino secundário (CLASSEC), com médias ( $M=144.26$, $\mathrm{DP}=16.54)$ e mínimos (110) superiores. Não obstante os máximos mais elevados (187) se verificarem nas provas de ingresso (PING), a maior dispersão traduz-se em médias mais baixas $(M=136.08$, $D P=1.27)$, que se repercutem na nota de candidatura (NC).

A grande maioria dos alunos (79\%) apresenta um padrão de estudo com regularidade, que se traduz em mais de três vezes por semana. Entre os restantes 44 alunos, $47,4 \%$ prefere estudar quando tem oportunidade e $39,5 \%$ próximo dos momentos de avaliação. O estudo individual aparece como preferência de $91,5 \%$ dos alunos, numa amostra onde $31,7 \%$ refere ter participado em actividades académicas de natureza extracurricular.

A maior parte dos alunos $(84,3 \%)$ encontra-se a frequentar o curso pretendido. No entanto, são $51 \%$ os que entraram para o par estabelecimento/curso de eleição e $48,6 \%$ fizeram a sua escolha em função do numerus clausus e a da probabilidade de colocação em função do número 
de vagas e nota de candidatura. Os 90,4\% de alunos que se dizem adaptados ao ensino superior (AES) atribuem aos colegas e amigos a maior participação nesse processo.

\subsection{Variáveis}

Consideram-se as variáveis cognitivas, operacionalizadas através de escalas de intervalos, de raciocínio numérico e verbal (PARC RN e RV, de 0 a 25 pontos cada) e de pensamento (IDCP - níveis dualista (IDCPcd e IDCPed), relativista (IDCPcr e IDCPer) e de compromisso (IDCPcc e IDCPec), dos conteúdos de Carreira e Educação, de 50 a 200 pontos por conteúdo), bem como o desempenho no ensino superior (DES - média de classificações obtidas, de 10 a 20 pontos). Utilizou-se, ainda, um índice global de pensamento (IDCP Final), calculado para cada subescala (IDCPfc e IDCPfe), a partir do somatório dos resultados obtidos no relativismo e compromisso, subtraindo-lhe os resultados de dualismo (IDCP Final $=$ [relativismo + compromisso] - dualismo) $)^{4}$.

\subsection{Procedimento}

A recolha de dados foi efectuada em 3 momentos (início em Outubro de 2003), com um ano de intervalo entre cada um, e realizou-se: (1) por administração directa em contexto de aula cedida pelos estabelecimentos/professores envolvidos, no que respeita aos elementos de desenvolvimento cognitivo (pensamento - IDCP e raciocínio - PARC); (2) por consulta dos processos individuais dos alunos, nos serviços académicos, para as classificações no ensino superior; e (3) por consulta dos dados referentes às notas de acesso, no site oficial ${ }^{5}$ de acesso ao ensino superior. Depois de explicados os objectivos e as instruções de preenchimento dos instrumentos, e dados a conhecer os restantes dados necessários, permitiuse aos alunos que não pretendiam colaborar a saída da sala. Os dados de identificação/caracterização foram recolhidos no primeiro momento (T1) de passagem do IDCP e da PARC.

\subsection{Instrumentos}

Para além de um Questionário de Identificação/Caracterização, construído para o efeito, foram utilizadas as subescalas de Educação e 
Carreira (num total de 50 itens cada) do Inventário de Desenvolvimento Cognitivo de Parker (IDCP), validado e aferido para a população portuguesa por Ferreira e Bastos (1995), e as provas de Raciocínio Verbal (RV) e Numérico (RN) das Provas de Avaliação da Realização Cognitiva (PARC), construída e validada por Ribeiro (1996), com 25 itens cada. O IDCP é uma escala de concordância, tipo Likert, de quatro pontos (1 a 4), enquanto a escala da PARC varia entre 0 e 25 pontos, correspondendo um ponto a cada item correctamente respondido.

Em termos de dados psicométricos do IDCP, os valores de consistência interna apontados pelos autores variam, nas duas subescalas consideradas, entre .68 e .78 (alfa de Cronbach), e o estudo de validade concorrente realizado com o Inventário de Personalidade de Jackson revelou resultados satisfatórios (Ferreira \& Bastos, 1995). Quanto à PARC, a consistência interna (Kuder-Richardson 20) apresentou índices de .83 e .89 (respectivamente para RV e RN) e a validade externa foi avaliada a partir da comparação entre resultados de alunos dos ensinos secundário e superior, tendo sido estatisticamente superiores neste últimos (Ribeiro, 1996).

\subsection{Análise de dados}

Atendendo ao tipo de estudo (com amostras emparelhadas), à natureza das variáveis (de intervalos) e aos objectivos (evolução dos resultados ao longo do ensino superior), as opções em termos de técnicas estatísticas recaíram sobre as que se revelaram mais pertinentes e ajustadas à situação. Porém, genericamente, recorreu-se a estatística paramétrica, uma vez que a única condição não verificada foi a que se refere à normalidade de algumas distribuições. Assim, e porque não há unanimidade nos autores relativamente a esta condição e muitos há que defendem como condições fundamentais para que se possam aplicar estatísticas paramétricas, quando não estão garantidas a homocedasticidade e a normalidade, as relativas às dimensões dos grupos, que têm que ser semelhantes (razão inferior a 1,5) e superiores ou iguais a 30 (Everitt, 1996; Glass \& Hopkins, 1996; Melo, 1985; Pestana \& Gageiro, 2003). Salienta-se a validação da esfericidade (nível de significância de .08, no teste de Mauchly), indispensável à utilização do teste $\mathrm{F}$ de medidas repetidas. 
Para além dos parâmetros de tendência central e de dispersão, seleccionaram-se as técnicas ajustadas à natureza, objectivos e hipóteses de estudo, que se concretizam em: coeficiente de correlação de Pearson (r), magnitude dos efeitos $(\mathrm{ME})^{6}$, análise da variância (teste $\mathrm{F}$ ) de medidas repetidas e coeficiente de correlação intraclasse $(R)^{7}$. Quanto a este último índice, optou-se pela utilização da classificação proposta por Pestana e Gageiro (2003), de muito boa $(\mathrm{R}>.9)$, boa $(.8<\mathrm{R} \leq .9)$, razoável $(.7<\mathrm{R} \leq .8)$, fraca $(6 \leq \mathrm{R} \leq .7)$ e inadmissível $(\mathrm{R}<.6)$.

No que respeita à magnitude dos efeitos, alertamos para a necessidade de colocar reservas nas situações de violação à normalidade e dispersão elevada, uma vez que se trata de um índice muito sensível ao desvio padrão. Valores muito elevados do desvio padrão podem anular diferenciais consideráveis entre as médias.

\section{Resultados}

\subsection{As mudanças no raciocínio}

Os resultados revelam uma melhoria no raciocínio ao longo das três avaliações realizadas, independentemente da natureza da prova (verbal ou numérica), ainda que com valores favoráveis ao raciocínio verbal (Figura 1).

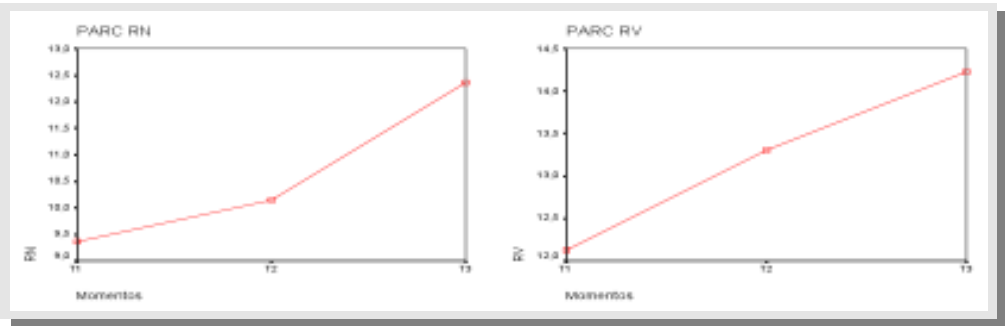

Figura 1 - Gráficos da distribuição das médias na PARC (raciocínios numérico - RN e verbal - RV) nos 3 momentos temporais (T1, T2 e T3)

Todavia, o padrão de crescimento em cada espaço temporal é distinto, acontecendo as maiores subidas de T1 para T2, em RV, e de T2 para T3, em $\mathrm{RN}$, o que aliás é reforçado pela análise da magnitude dos efeitos (Quadro 2), com ganhos moderados de T1 para T2 e fracos de T2 para T3, no caso da 
prova verbal, e moderados nos dois períodos (.33SD e .41SD), na prova numérica. Os ganhos nas duas subescalas de raciocínio, entre T1 e T3 são moderados em RV (.65SD) e elevados em RN (.74SD), o que, aliado ao padrão evolutivo anterior de cada prova, nos remete para um desenvolvimento mais tardio do conteúdo numérico.

Quadro 2 - Magnitude dos efeitos (ME) na PARC (raciocínios numérico - RN e verbal - RV), em unidades de desvio padrão (SD)

\begin{tabular}{cccc|ccc|}
\hline & \multicolumn{3}{c|}{ RN } & \multicolumn{3}{c}{ AV } \\
\hline & T1 & T2 & T3 & T1 & T2 & T3 \\
M & 9.39 & 10.68 & 12.3 & 12.13 & 13.3 & 14.23 \\
SD & 3.93 & 3.96 & 4.33 & 2.91 & 3.79 & 3.85 \\
\hline & T2-T1 & T3-T2 & T3-T1 & T2-T1 & T3-T2 & T3-T1 \\
ME & .33 & .41 & .74 & .59 & .05 & .65 \\
\hline
\end{tabular}

Ambas as provas de raciocínio se correlacionam positiva e significativamente (Quadro 3), nos três momentos considerados, e os valores mais elevados atingem-se em T3 $(r=.361, p=.000)$. No entanto, em termos de comportamento por prova, todas as correlações em RN são positivas e altamente significativas, nos diferentes tempos (entre .418 e .497), e bastante superiores às encontradas no raciocínio verbal, que não têm mesmo significado estatístico entre T1 e T3. Aliás, o coeficiente de correlação intraclasse $(\mathrm{R})$ traduz valores razoáveis em $\mathrm{RN}$, com $\mathrm{R}=.73$ [IC95 = $(.62, .81)]$ e mostra um nível de estabilidade inadmissível em $\mathrm{RV}(\mathrm{R}=.39$ [IC95 = (.14, .57)]), ou seja, os desempenhos verbais parecem não depender dos obtidos num tempo anterior. 
Quadro 3 - Medidas repetidas (teste F) e correlações (r de Pearson) intra e inter-momentos na PARC (raciocínios numérico - RN e verbal - RV)

\begin{tabular}{|c|c|c|c|c|c|c|c|c|c|c|}
\hline \multicolumn{7}{|c|}{ Medidas repetidas } & \multicolumn{4}{|c|}{ Correlaçōes } \\
\hline PARC & $\begin{array}{l}\text { Fonte de } \\
\text { variaçẫo }\end{array}$ & so & gl & $Q M$ & $\mathrm{~F}$ & p & PARC & $\mathrm{T} 1{ }^{*} \mathrm{~T} 2$ & T2*T3 & T1'T3 \\
\hline RN & $\begin{array}{l}\text { Inter-amostras } \\
\text { Intra-amostras }\end{array}$ & $\begin{array}{l}473.882 \\
1954.78\end{array}$ & $\begin{array}{c}2 \\
190\end{array}$ & $\begin{array}{c}236.941 \\
10.28\end{array}$ & 23.030 & .000 & RN & $.466^{* * *}$ & $.418^{+* * *}$ & $.497^{* * *}$ \\
\hline T1 vs. T2 & $\begin{array}{l}\text { Inter-amostras } \\
\text { Intra-amostras }\end{array}$ & $\begin{array}{c}90.094 \\
1512.90\end{array}$ & $\begin{array}{c}1 \\
95\end{array}$ & $\begin{array}{c}90.094 \\
15.92\end{array}$ & 5.657 & .019 & N & 176 & 96 & 106 \\
\hline T2 vs. T3 & $\begin{array}{l}\text { Inter-amostras } \\
\text { Intra-amostras }\end{array}$ & $\begin{array}{l}425.042 \\
2234.95\end{array}$ & $\begin{array}{c}1 \\
95\end{array}$ & $\begin{array}{c}425.042 \\
23.52\end{array}$ & 18.067 & .000 & RV & $.210^{* *}$ & $.201^{*}$ & .112 \\
\hline RV & $\begin{array}{l}\text { Inter-amostras } \\
\text { Intra-amostras }\end{array}$ & $\begin{array}{l}213.521 \\
1970.47\end{array}$ & $\begin{array}{c}2 \\
190\end{array}$ & $\begin{array}{c}108.760 \\
10.37\end{array}$ & 10.294 & .000 & N & 176 & 96 & 106 \\
\hline T1 vs. T2 & $\begin{array}{l}\text { Inter-amostras } \\
\text { Intra-amostras }\end{array}$ & $\begin{array}{l}133.010 \\
1729.99\end{array}$ & $\begin{array}{c}1 \\
95\end{array}$ & $\begin{array}{c}133.010 \\
18.21\end{array}$ & 7.304 & .008 & $\mathrm{RN}^{*} \mathrm{RV}$ a) & $.244^{*+*}$ & $.226^{* *}$ & $.361^{* * *}$ \\
\hline T2 vs. T3 & $\begin{array}{l}\text { Inter-amostras } \\
\text { Intra-amostras }\end{array}$ & $\begin{array}{r}82.510 \\
2216.49\end{array}$ & $\begin{array}{c}1 \\
95\end{array}$ & $\begin{array}{c}82.510 \\
23.33\end{array}$ & 3.536 & .063 & N & 331 & 176 & 106 \\
\hline
\end{tabular}

a) Os valores da linha referem-se, apenas, a cada um dos momentos (T1, T2, T3). * $\mathrm{p} \leq .05 ;{ }^{* *} \mathrm{p} \leq .01 ;{ }^{* *} \mathrm{p} \leq .001$.

$\mathrm{Na}$ análise das medidas repetidas (Quadro 3), verificam-se mudanças estatisticamente significativas, nos dois tipos de raciocínio, ao longo dos três momentos considerados $(F(2)=23.030 ; p=.000$, em $R N$ e $F(2)=10.294 ; p=$ .000 , em RV), não obstante valores não significativos na prova verbal, de T2 para T3. Acresce a confirmação destas diferenças entre T1 e T3, no Bonferroni, concluindo-se, assim, por uma melhoria de desempenhos verbais e numéricos, ou seja, está em evidência um crescimento/desenvolvimento ao longo do ensino superior, sobretudo do primeiro para o segundo momento, no caso de RV.

\subsection{As mudanças no pensamento}

No que respeita ao pensamento, o padrão evolutivo dos índices finais (Carreira e Educação) apresenta perdas entre T1 e T2, menores na Carreira (-.10SD contra -.17SD), que a subida registada no segundo período temporal (T2 para T3) não compensa (Figura 2). Ainda que com valores de pequena magnitude (Quadro 4), assistimos a uma maior variação na Educação, tanto na descida (-.27SD contra -.14SD, na Carreira), já próxima do limiar moderado, como na subida (.10SD contra .04). 
Figura 2 - Gráficos da distribuição das médias no IDCP (Carreira e Educação - índices finais) nos 3 momentos temporais (T1, T2 e T3)

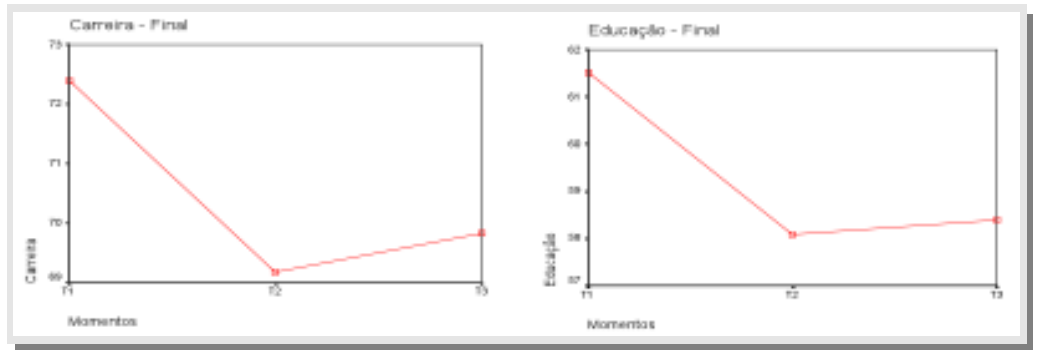

Quadro 4 - Magnitude dos efeitos (ME) no IDCP, em unidades de desvio-padrão (SD)

\begin{tabular}{|c|c|c|c|c|c|c|c|}
\hline IDCP & Tempo & $\mathbf{N}$ & $M$ & DP & T2-T1 & T3-T2 & T3-T1 \\
\hline \multirow{3}{*}{ IDCPed } & $\mathrm{T} 1$ & 206 & 38.36 & 3.65 & & & \\
\hline & $\mathrm{T} 2$ & 176 & 35.83 & 3.60 & -.15 & .05 & -.20 \\
\hline & T3 & 108 & 35.67 & 4.25 & & & \\
\hline \multirow[t]{3}{*}{ IDCPCr } & T1 & 205 & 54.26 & 4.70 & & & \\
\hline & T2 & 177 & 53.16 & 4.23 & .26 & $\cdot, 10$ & -36 \\
\hline & T3 & 109 & 52.71 & 3.75 & & & \\
\hline \multirow[t]{3}{*}{$10 C P \propto \infty$} & $\mathrm{T1}$ & 205 & 52.29 & 4.31 & & & \\
\hline & $\mathrm{T} 2$ & 171 & 51.74 & 3.99 & -.13 & 11 & -.02 \\
\hline & T3 & 107 & 52.49 & 4.60 & & & \\
\hline \multirow[t]{3}{*}{ IDCPfe } & T1 & 201 & 40.74 & 5.25 & & & \\
\hline & $\mathrm{T} 2$ & 176 & 41.39 & 5.75 & -.14 & .04 & -.10 \\
\hline & T3 & 106 & 40.77 & 6.41 & & & \\
\hline \multirow[t]{3}{*}{ IDCPed } & $\mathrm{T} 1$ & 206 & 50.21 & 4.20 & & & \\
\hline & T2 & 174 & 49.07 & 4.27 & .11 & $\cdot, 11$ & 0 \\
\hline & $\mathrm{T} 3$ & 105 & 49.12 & 3.83 & & & \\
\hline \multirow[t]{3}{*}{ IDCPer } & $\mathrm{T} 1$ & 206 & 50.53 & 4,11 & & & \\
\hline & T2 & 174 & 49.71 & 4.34 & -.27 & .01 & -.26 \\
\hline & $\mathrm{T} 3$ & 109 & 49.87 & 4.12 & & & \\
\hline \multirow[t]{3}{*}{ IDCPEC } & $\mathrm{T} 1$ & 194 & 70.56 & 9.21 & & & \\
\hline & T2 & $16 \mathrm{~B}$ & 69.27 & 9.03 & .20 & .04 & $\cdot, 16$ \\
\hline & T3 & 106 & 69.63 & 9.69 & & & \\
\hline \multirow[t]{3}{*}{ IDCPfe } & $\mathrm{T} 1$ & 195 & 60.20 & 10.35 & & & \\
\hline & T2 & $16 \mathrm{~B}$ & 57.35 & 10.40 & -27 & .10 & -17 \\
\hline & $\mathrm{T} 3$ & 103 & 59.36 & 10.99 & & & \\
\hline
\end{tabular}

Legenda: cd (carreira dualismo); cr (carreira relativismo); cc (carreira compromisso); fc (final carreira); ed (educação dualismo); er (educação relativismo); ec (educação compromisso); fe (final educação).

A análise por nível de pensamento (Quadro 5) permite perceber que os resultados finais se devem, sobretudo, às perdas no relativismo e compromisso (Carreira e Educação), uma vez que há uma evolução positiva no dualismo do conteúdo Carreira (menos dualistas). Quanto à Educação, o 
declínio de T2 para T3 (-.11SD) na posição dualista apenas anula a subida de T1 para T2 (.11SD). A tendência para o movimento regressivo do primeiro para o segundo momento começa a evidenciar sinais de melhoria entre T2 e T3, ainda que muito ligeiros em unidades de desvio-padrão (entre .01SD. e 11SD), à excepção do relativismo da Carreira, com perdas em ambos os períodos.

\section{Quadro 5 - Correlações intra e inter-momentos e coeficiente intraclasse} (R), no IDCP

\begin{tabular}{|c|c|c|c|c|}
\hline IDCP & $\mathrm{T} 1 * \mathrm{~T} 2$ & T2*T3 & $\mathrm{T1}{ }^{*} \mathrm{~T} 3$ & A \\
\hline IDCPcd & $.415^{* * *}$ & $.282^{* *}$ & $.485^{* * *}$ & $.66[1 \mathrm{Cg} 5=(.52, .77)]$ \\
\hline IDCPCr & $.329^{* * *}$ & $410^{* * *}$ & $.288^{* *}$ & $.63[1 \mathrm{C} 95=(.48, .74)]$ \\
\hline IDCPCC & $.412 * *$ & $329^{* * *}$ & $.243^{*}$ & $.59[1 \mathrm{Cg} 5=(.42, .72)]$ \\
\hline IDCPfC & $378 * * *$ & $.462 * * *$ & $.407^{* * *}$ & $.70[1095=(.57, .80)]$ \\
\hline IDCPed & $.329^{* * *}$ & $.571^{* * *}$ & $.369 * * *$ & $.68[1 \mathrm{Cg} 5=(.55, .78)]$ \\
\hline IDCPer & $.432 * * *$ & $390^{* * *}$ & $.434^{* * *}$ & $.67[1095=(.54, .78)]$ \\
\hline IDCPeC & $394^{* * *}$ & $.288^{* *}$ & $.321 * * *$ & $.60[1 \mathrm{C} 95=(.44, .73)]$ \\
\hline IDCPfe & $.418^{* * *}$ & $.528^{* * *}$ & $.486^{* * *}$ & $.73[1 \mathrm{Cg} 5=(.61, .82)]$ \\
\hline CARR'EDUC a) & $.775^{* * *}$ & $.688 * * *$ & $.791 * * *$ & \\
\hline
\end{tabular}

Legenda: cd (carreira dualismo); cr (carreira relativismo); cc (carreira compromisso); fc (final carreira); ed (educação dualismo); er (educação relativismo); ec (educação compromisso); fe (final educação).

a) Refere-se a correlações entre os índices finais da Carreira e Educação, em cada momento (T1, T2 e T3). * $\mathrm{p} \leq .05 ;{ }^{* *} \mathrm{p} \leq .01 ;{ }^{* * *} \mathrm{p} \leq .001$.

É de salientar as correlações positivas e altamente significativas entre os desempenhos nos três momentos de avaliação (Quadro 5), em todos os níveis das duas subescalas, apesar das variações inter-momentos, revelando coerência de performance, que é reforçada pela estabilidade identificada nos coeficientes razoáveis de correlação intraclasse no IDCP Final $(R=.70$ [IC95 $=(.57, .80)]$, na Carreira, e $R=.73$ [IC95 $=(.61, .82)]$, na Educação). 
Quadro 6 - Medidas repetidas (teste F) no IDCP

\begin{tabular}{llccccccc|}
\hline IDCP & $\begin{array}{c}\text { Fonte de } \\
\text { variaçấ }\end{array}$ & SQ & gl & QM & F & P & T \\
\hline IDCPcd & Inter-amostras & 7.326 & 2 & 3.663 & .378 & .686 & \\
& Intra-amostras & 1762.00 & 182 & 9.68 & & & \\
IDCPCr & Inter-amostras & 244.799 & 2 & 122.399 & 10.377 & .000 & T1vsT2** \\
& Intra-amostras & 2241.20 & 190 & 11.79 & & & \\
IDCPcC & Inter-amostras & 96.116 & 2 & 48.058 & 3.946 & .021 & T1vsT2** \\
& Intra-amostras & 2216.55 & 182 & 12.17 & & & \\
IDCPic & Inter-amostras & 476.369 & 2 & 238.185 & 4.787 & .010 & T1vsT2** \\
& Intra-amostras & 8160.29 & 164 & 49.75 & & & \\
\hline IDCPed & Inter-amostras & 22.326 & 2 & 11.163 & .571 & .566 & \\
& Intra-amostras & 3559.67 & 182 & 19.55 & & & \\
IDCPer & Inter-amostras & 104.274 & 2 & 52.137 & 5.268 & .006 & T1vsT2* \\
& Intra-amostras & 1761.72 & 178 & 9.89 & & & \\
IDCPec & Inter-amostras & 75.744 & 2 & 37.872 & 3.185 & .044 & T1vsT2* \\
& Intra-amostras & 2140.25 & 180 & 11.89 & & & \\
IDCPie & Inter-amostras & 584.025 & 2 & 292.012 & 5.185 & .007 & T1vsT2** \\
& Intra-amostras & 9011.30 & 160 & 56.32 & & & \\
\hline
\end{tabular}

Legenda: cd (carreira dualismo); cr (carreira relativismo); cc (carreira compromisso); fc (final carreira); ed (educação dualismo); er (educação relativismo); ec (educação compromisso); fe (final educação). ${ }^{*} p \leq .05 ;{ }^{* *} p \leq .01 ;{ }^{* \star} p \leq .001$.

As descidas nos índices finais do pensamento, bem como no relativismo e compromisso, dos dois conteúdos, revelam-se estatisticamente significativas na análise de medidas repetidas (Quadro 6), o que se deve, essencialmente, ao primeiro intervalo de tempo (de T1 vs T2), como podemos constatar no Quadro 6. Evidenciaram-se, assim, alterações estatísticas, de sentido regressivo, nos níveis de pensamento relativista e de compromisso, ao longo do ensino superior, com índices de estabilidade aceitáveis.

\subsection{As mudanças no desempenho}

Genericamente, verifica-se que as classificações dos alunos no ensino superior sobem ao longo dos três momentos de avaliação (Figura 3), com ganhos na magnitude dos efeitos (Quadro 7) elevados de T1 para T2 e moderados de T2 para T3, traduzidos em valores finais de 1.18SD. As médias de classificação apresentam-se positiva e significativamente correlacionadas, nos três momentos (Quadro 6.44), ainda que em T1 os valores sejam mais pequenos. As correlações positivas elevadas (entre .614 e .667) entre as três 
recolhas, juntamente com um índice de estabilidade bom $(R=.84)$, ilustram a dependência dos desempenhos posteriores, relativamente aos anteriores.

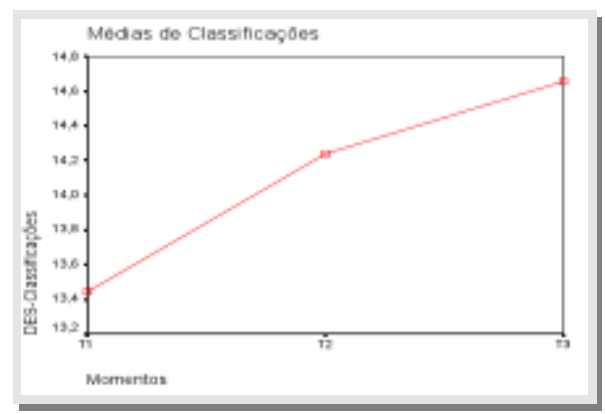

Figura 3 - Gráfico da distribuição das médias no DES (média de classificações) nos 3 momentos temporais (T1, T2 e T3)

A análise de medidas repetidas (Quadro 7) constitui-se como um reforço dos demais resultados, no que se refere à melhoria estatística das classificações durante os três momentos.

Quadro 7 - Magnitude dos efeitos (teste F) e correlações intra e intermomentos e intraclasse (R), no DES (média de desempenho)

\begin{tabular}{|c|c|c|c|c|c|c|c|}
\hline DES & Tempo & $\mathrm{N}$ & M & DP & T2-T1 & T3-T2 & T3-T1 \\
\hline \multirow{8}{*}{ MED } & T1 & 210 & 13.44 & .99 & \multirow{3}{*}{.77} & \multirow{3}{*}{.41} & \multirow{3}{*}{1.18} \\
\hline & T2 & 201 & 14.23 & .90 & & & \\
\hline & T3 & 139 & 14.65 & 1.19 & & & \\
\hline & \multicolumn{2}{|l|}{$\mathrm{T} 11^{*} \mathrm{~T} 2$} & T2*T3 & T1'T3 & \multicolumn{3}{|c|}{$\mathbf{R}$} \\
\hline & \multicolumn{2}{|c|}{$.640^{\cdots \cdots}$} & $.667^{* *}$ & $.614^{\cdots *}$ & \multicolumn{3}{|c|}{$\mathrm{R}=.84[1 \mathrm{C} 95=(.78, .88)]$} \\
\hline & \multicolumn{2}{|l|}{ so } & gl & $Q M$ & \multicolumn{2}{|c|}{$\mathbf{F}$} & p \\
\hline & \multicolumn{2}{|c|}{104.934 a) } & 2 a) & $52.467 \mathrm{a})$ & \multirow{2}{*}{\multicolumn{2}{|c|}{133.179}} & .000 \\
\hline & 107.945 & & 274 b) & $.394 \mathrm{~b})$ & & & \\
\hline \multirow[t]{2}{*}{ T1 vs. T2 } & \multicolumn{2}{|c|}{$86.862 \mathrm{a})$} & 1 a) & $86.862 \mathrm{a})$ & \multicolumn{2}{|c|}{149.144} & .000 \\
\hline & 79.789 & & $137 \mathrm{~b})$ & $.582 \mathrm{~b})$ & \multirow{3}{*}{\multicolumn{2}{|c|}{30.525}} & .000 \\
\hline \multirow[t]{2}{*}{ T2 vs. T3 } & \multicolumn{2}{|c|}{24.452 a) } & 1 a) & 24.452 a) & & & \\
\hline & 109.745 & & $137 b)$ & $.801 \mathrm{~b})$ & & & \\
\hline
\end{tabular}

a) fonte de variação inter-amostras.

b) fonte de variação intra-amostras.

${ }^{*} \mathrm{p} \leq .05 ;{ }^{* *} \mathrm{p} \leq .01 ;{ }^{* \star *} \mathrm{p} \leq .001$. 


\section{Discussão dos resultados}

\subsection{Mudanças nas provas de raciocínio}

Não obstante a tendência para o declínio das aptidões cognitivas, a partir do jovem adulto e/ou adulto emergente, evidenciada na literatura (Ribeiro, 1996), é claro o potencial de influência dos contextos vivenciais no seu desenvolvimento, incluindo o contexto escolar (Berg, 1992; Blackburn \& Papalia, 1992; Snow, 1989, 1994).

Em Portugal, Almeida (1988), Ribeiro (1996) e Pinto (2003) põem em evidência uma subida nos desempenhos em provas de aptidão e raciocínio, em alunos do ensino secundário e do ensino superior.

Também Pascarella e Terenzini $(1991,2005)$ se referem a múltiplos trabalhos com ganhos significativos, do primeiro para o último ano do ensino superior, com variação entre .56SD e .77SD nas competências verbais, e .24SD e .55SD nas numéricas (respectivamente, em 1991 e 2005). No mesmo sentido apontam os resultados de Bowen (1977), Osterlind (1996, 1997) e Flowers, Osterlind, Pascarella \& Pierson (1999), com diferenciais entre caloiros e finalistas a oscilar dos .50SD aos .77SD, a nível verbal, e .20SD e .44SD, em provas numéricas.

Muitos outros autores encontraram ganhos numéricos e/ou verbais em função do maior número de anos de exposição pós-secundária (Bohr et al.; 1994; Myerson et al., 1998; Pascarella, Bohr, Nora, \& Terenzini, 1995) ou envolvimento escolar (Flowers \& Pascarella, 1999; Hagedorn et al.,1997). Esta tendência é confirmada em estudos longitudinais (Underwood et al. 1996; Thorndike \& Andrieu-Parker, 1992) e naqueles que comparam indivíduos com e sem frequência do ensino superior (incrementos verbais entre .26SD e .32SD, e numéricos entre .29SD e .32SD) (Pascarella \& Terenzini, 1991). No entanto, num trabalho realizado por Ransdell et al. (2001), com duas subamostras (estoniana e americana), os resultados foram distintos, com correlações positivas entre o número de anos no ensino superior e a aptidão verbal, na subamostra estoniana, e correlações negativas na subamostra americana.

De acordo com Pascarella e Terenzini (1991, 2005), na globalidade, os resultados mostram que é mais fácil aumentar níveis de realização mais baixos e que $90 \%$ dos ganhos acontecem nos primeiros dois anos, o que é corroborado por Osterlind (1996, 1997). 


\subsection{Mudanças no pensamento}

Em termos do pensamento, os nossos resultados não são coincidentes com o grande número de evidências disponíveis na literatura que, maioritariamente, sustentam um impacto positivo da frequência do ensino superior.

Encontramos, na literatura, diversas referências que mostram ganhos (em estudos longitudinais) ou melhores resultados (em estudos transversais), ao longo do ensino superior, nos constructos normalmente aglutinados na designação de pensamento pós-formal (Baxter-Magolda \& Porterfield, 1985; King \& Kitchener, 1994; Mines et al., 1990; Kitchener \& Wood, 1987; Kitchener, Wood \& Jensen, 1999; Perkins, 1985; Whitla, 1978; Wood, 2000).

Também estudos portugueses põem em evidência um impacto positivo da frequência do ensino superior, traduzido em descidas nas formas dualistas de pensar dos estudantes e aumento concomitante no relativismo e compromisso, em designs transversais que utilizaram, também, o IDCP (Bastos, 1998; Ferreira \& Bastos, 1995; Medeiros et al. 2002), ou outro instrumento (Faria \& Bastos, 2005). Todavia, outros há que se distanciam daqueles, ao concluírem por menores evidências no desenvolvimento das formas de pensar, à semelhança do nosso estudo. Assim, Medeiros et al. (2002) encontraram, sobretudo, um pensamento menos dualista, no IDCP, em alunos do último ano, para além de um comportamento oscilante no relativismo e compromisso, incluindo descidas (compromisso da Religião nos alunos de Engenharia do Ambiente). Pereira e Medeiros (2005), com alunos de Enfermagem (população de onde provém parte dos alunos da nossa amostra), constataram uma diminuição no dualismo do $1^{\circ}$ para o $3^{\circ}$ ano, mas com inflexão no $4^{\circ}$ ano (tornam-se, novamente, mais dualistas), enquanto no relativismo e compromisso não se registaram alterações significativas. Também Martins (2005, 2007), com alunos provenientes dos estabelecimentos aqui considerados e da área das tecnologias, obteve níveis de pensamento na Carreira e no compromisso da Educação mais favoráveis no $1^{\circ}$ ano do que em finalistas.

A maior incidência das mudanças significativas no primeiro período temporal (entre T1 e T2) corrobora outros estudos que remetem para a superioridade do impacto inicial (durante $01^{\circ}$ ano), que diminui, progressivamente, com a exposição ao ensino superior (Bastos, 1998; 
Facione, 1997; Pascarella, Polmer, Moye, \& Pierson, 2001; Saucier, 1995). Não obstante, King e Kitchener (1994), a partir de uma síntese da literatura, constatam maiores alterações em períodos inter-avaliação mais longos.

\subsection{Mudanças no desempenho}

A evolução positiva do desempenho dos alunos no ensino superior não parece surpreender, uma vez que se ajusta a outros estudos realizados em Portugal (Lencastre, Guerra, Lemos, \& Pereira 2000; Marques \& Miranda, 1991; Martins, 1993; Mendes, 2006) e deve corresponder à conjugação de diversos factores, entre os quais se destacam: a adaptação ao ensino superior (Pinheiro, 2003); a natureza das disciplinas, que se tornam mais específicas à actividade profissional do curso frequentado, facilitando a visão da sua instrumentalidade; e, finalmente, a proximidade com o final do curso, que aumenta a preocupação com a classificação final, face à concorrência no mercado de trabalho.

\section{Conclusão}

\subsection{Perfis das mudanças}

Independentemente de se tratar de mudanças cognitivas ocorridas durante o período de frequência do ensino superior ou de alterações que representam desenvolvimento, o estudo do impacto da escolaridade pós-secundária tem vindo a revelar efeitos positivos. No entanto, a amostra abrangida pelo trabalho aqui apresentado revelou um comportamento algo heterogéneo, dependendo do outcome em causa. Ainda que se verifiquem alterações estatisticamente significativas, elas distinguem-se em termos de sentido e de estabilidade, quer em função do tipo de variável, quer em função do nível e/ou conteúdo a que se reportam. Assim, no que respeita à realização cognitiva (raciocínio numérico e verbal) e académica (desempenho), assistimos a subidas estatisticamente significativas, por contraste com resultados contraditórios e, aparentemente, paradoxais na cognição epistémica (pensamento). Com efeito, os alunos assumem posições menos relativistas e de menor compromisso, e o pensamento menos dualista revelado não tem relevo estatístico. A ideia veiculada pela literatura, de maior contributo do primeiro ano de ensino superior para as alterações, não é aqui 
corroborada, em virtude do comportamento distinto nas variáveis de natureza cognitiva (raciocínio e pensamento). As diferenças nos dois conteúdos de raciocínio e nos níveis e conteúdos de pensamento reforçam o argumento de especificidades inerentes às diferentes capacidades intelectuais.

Face aos resultados, realçamos o que pode contrariar, em certa medida, o esperado, sobretudo pelas implicações que pode ter para a reflexão sobre o papel do ensino superior no desenvolvimento integral do indivíduo. Do ponto de vista teórico, relembramos que o próprio Perry (1970) previu retrocessos a formas anteriores de pensamento, como resposta a pressões demasiado elevadas. Por outro lado, sabemos quão melindrosa é, desse ponto de vista, a fase de transição ou adaptação ao ensino superior, o que, aliás, é reforçado pelas descidas do primeiro para o segundo momento e pelas subidas, ainda que ligeiras, do segundo para o terceiro. Não parece, pois, que se trate de uma verdadeira regressão ou perda de capacidades, no que respeita à consciência adquirida sobre a incerteza irredutível extensiva a toda a esfera do conhecimento, ou mesmo na comparação de pressupostos, processos e sistemas lógicos. Afiguram-se-nos, como mais prováveis, paragens ou recuos na interiorização da responsabilidade e iniciativa que, na posição dualista, pertenciam a uma autoridade externa. É aqui que, em nossa opinião, podem os contextos escolares e a sua organização contribuir para que o desenvolvimento se processe num ou noutro sentido.

A percepção de que assumir uma posição mais absolutista, de conformismo a perspectivas e modelos que the são veiculados, facilita alcançar o objectivo de melhores resultados académicos, que permitam mais oportunidades profissionais, pode levar os alunos a adoptar, temporariamente, essa atitude. Sendo assim, estamos perante um posicionamento instrumental, que pode ser intencional, ou sem preocupações de acto deliberado. Não é novidade, em termos de desenvolvimento, estar em determinado nível e recorrer a formas de funcionamento pertencentes a uma posição anterior e inferior, do ponto de vista da complexidade.

Do exposto, poderão não ser preocupantes os resultados obtidos, do ponto de vista da desadequação com o referencial teórico ou dos efeitos reais provocados nos alunos, mas exige-se uma reflexão sobre os contextos de ensino a nível superior. Lembramos que a amostra, em estudo pertence ao subsistema politécnico, população abrangida, aliás pelos estudos de Bastos 
et al. (2003) e Martins (2005, 2007), onde se encontraram resultados próximos. Não obstante o trabalho de Pereira e Medeiros (2005) ter incidido em alunos da Universidade dos Açores, trata-se de um curso de enfermagem que está, normalmente, inserido no politécnico (como é o caso dos alunos do estudo presente). Ressalta daqui uma variabilidade inter-institucional que, podendo significar uma influência dos modelos, métodos e formas de organização do ensino, deixa antever a necessidade de uma reflexão assente na investigação fundamental e aplicada, que permita conhecer variáveis e condições facilitadoras, para além de se alterarem, intencionalmente, práticas. O objectivo é potenciar o impacto positivo do ensino superior, que se pretende seja, cada vez mais, resposta efectiva às necessidades de formação inerentes aos desafios da globalização e do século XXI. Conscientes desta realidade, acreditamos na capacidade de superar a resistência à mudança das instituições de ensino superior, que é, neste momento, o obstáculo de maior dimensão. Sabemos, contudo, que não é fácil: basta confrontarmo-nos com as dificuldades sentidas a propósito do já grande passo nesse sentido que é o Processo de Bolonha, em curso.

\subsection{Limitações e pistas para o futuro}

Importa registar algumas limitações que devem ser ponderadas a propósito das interpretações e alcance dos resultados obtidos, ao mesmo tempo que se sugerem orientações para futuros trabalhos. Por um lado, a adopção de uma metodologia quantitativa, com todos os argumentos que the são favoráveis, não permite a compreensão, pela via da exploração, dos aspectos individuais e específicos, que os próprios resultados indiciam, mas que só se consegue alcançar com recurso a uma metodologia qualitativa. Não obstante o recurso a um design longitudinal, ultrapassando uma das limitações da investigação neste domínio, reconhecemos a necessidade de prolongar as avaliações no tempo, até ao final do curso, para podermos perceber se há ganhos efectivos ou se, pelo contrário, os eventualmente registados servem apenas para compensar perdas durante o primeiro ano.

A amostra utilizada exclui estratos da população estudantil do ensino superior habitualmente não incluídos, mas que começam a crescer em termos de representatividade neste nível de ensino (alunos não tradicionais e de pós-graduações). Ainda, os alunos que não prosseguiram estudos 
constituem-se como um grupo de contraste imprescindível, sobretudo num campo em que a principal dificuldade reside na identificação da especificidade dos efeitos atribuíveis ao ensino superior. Igualmente, as características da amostragem e a falta de representatividade da população abrangida em termos de ensino superior não permitem generalizações, não obstante a percentagem elevada de alunos relativamente à população (79,5\%).

Quanto aos instrumentos, foram escolhidos os que se apresentam validados e aferidos para a população portuguesa, pese embora a dificuldade decorrente da não existência de um valor global no IDCP. Salientamos o largo caminho a percorrer, em Portugal, no campo da construção de instrumentos de avaliação psicológica, que pode estar a ser prejudicada pela urgência da investigação aplicada.

No que às variáveis diz respeito, importa ponderar e integrar outros aspectos do desenvolvimento, igualmente importantes, como constructos cognitivos diferentes, e encarar o êxito no ensino superior numa perspectiva mais abrangente, i.e., para além do rendimento. Com efeito, no domínio do impacto do ensino superior, há um mundo a explorar, designadamente aspectos inerentes ao envolvimento académico, ao comportamento de estudo, às características institucionais, à adaptação ao ensino superior, às características dos cursos, aos métodos e estratégias de ensino/aprendizagem, aos perfis de formação exigidos e ao acompanhamento dos alunos. Em última instância, conhecer o impacto do ensino superior exige que se "mergulhe nele", ou seja, nas aulas, nos professores, nos métodos e estratégias, nas competências, etc., que não se avaliam pelo desempenho, nem por outcomes cognitivos descontextualizados. Investigações desta natureza terão muito a beneficiar da utilização de análises estatísticas estruturais, que identifiquem efeitos indirectos mediados, para além dos efeitos combinados, compreendendo melhor a direcção e o posicionamento relativo de variáveis intervenientes e respondendo às exigências da complexidade envolvida.

\section{Notas}

1 Salienta-se que a primeira obra dos autores já é um segundo volume de uma série de três publicados pela editora Jossey-Bass, com objectivos de uma revisão 
compreensiva da literatura relativa aos estudos sobre o impacto do ensino superior. A primeira obra, The Impact of College on Students, da autoria de Kenneth Feldman e Theodore Newcomb, foi publicada em 1969 e revê cerca de 1500 estudos.

2 Considerou-se a classificação proposta por Simões (1994) e adaptada por Matos (2004), que assenta em três níveis (baixo, médio e elevado).

3 As classificações de acesso ao ensino superior compreendem as classificações do secundário (CLASSEC), das provas de ingresso (PING) e a nota de candidatura (NC).

4 Trata-se de um índice não considerado pelos autores do instrumento e, por isso mesmo, não testado. Todavia, surgiu da necessidade de uma medida global de pensamento, que permita contornar a dificuldade decorrente da existência de três níveis em simultâneo, com evolução independente. Não obstante os valores de alfa de Cronbach encontrados para este índice se situarem entre .80 e .84, subsistem fragilidades que nos exigem prudência nas interpretações e conclusões.

5 www.acessoensinosuperior.pt

6 A magnitude dos efeitos foi estimada em unidades de desvio-padrão (SD), a partir do quociente da diferença entre as médias obtidas entre dois momentos e o desvio padrão global (relativo aos dois momentos). Apesar de algum desacordo quanto ao significado a conferir aos resultados de effect size obtidos, a literatura parece evidenciar maior consenso em considerar pequenos valores inferiores a .30, moderados entre .30 e .70 e elevados acima de .70 (Pascarella \& Terenzini, 2005).

7 O coeficiente de correlação intraclasse (average measure intraclass correlation - R) é um índice estatístico, de consistência interna, que permite aferir da estabilidade da mudança. Neste caso, em que medida os sujeitos, quando mudam, mantêm entre si as posições relativas ocupadas (Maia, Silva, Seabra, \& Lopes, 2002; Pinheiro, 2003). A escala a utilizar para classificar os valores de $R$ é a mesma que se utiliza para a consistência interna.

\section{Referências}

Almeida, A. (2004). Cognição como Resolução de Problemas: Novos Horizontes para a Investigação e Intervenção em Psicologia e Ciências da Educação. Tese de Doutoramento não publicada. Coimbra: Universidade de Coimbra, Faculdade de Psicologia e de Ciências da Educação.

Almeida, L. (1986). Bateria de Provas de Raciocínio Diferencial. Porto: Universidade do Porto, Faculdade de Psicologia e de Ciências da Educação.

Almeida, L. (1988). Diferenças de sexo e de classe social em testes de raciocínio: estudo junto de alunos do ensino secundário. Revista Portuguesa de Pedagogia, XXII, 111-137.

Almeida, L., \& Campos, B. P. (1986). Validade preditiva dos testes de raciocínio diferencial. Cadernos de Consulta Psicológica, 2, 105-118. 
Almeida, L., Santos, A. C., Dias, P. B., Botelho, S., \& Ramalho, V. (1998). Dificuldades de adaptação e de realização académica no Ensino Superior: Análise de acordo com as escolhas vocacionais e o ano de curso. Revista Galego-Portuguesa de Psicoloxia e Educación, 2, 41-48.

Almeida, L., Soares, A. P., \& Ferreira, J. (1999). Adaptação, rendimento e desenvolvimento dos estudantes do ensino superior: Construção e validação do Questionário de Vivências Académicas. Braga: Universidade do Minho, Centro de Estudos em Educação e Psicologia.

Anaya, G. (1996). College experiences and student learning: The influence of active learning, college environments, and curricular activities. Journal of College Student Development, 37, 611-622.

Anaya, G. (1999). Accuracy of student-reported test scores: Are they suited for college impact assessment? Unpublished manuscript. Indiana University, Bloomington.

Angoff, W., \& Johnson, E. (1990). The differential impact of curriculum on aptitude test scores. Journal of Educational Measurement, 27, 291-305.

Astin, A. (1993). What matters in college? Four critical years revisited. San Francisco: Jossey-Bass Publishers.

Barros, A., Fernandes, N., Almeida, L., \& Primi, R. (1999). Bateria de Provas de Raciocínio: relacionamento com o rendimento escolar e diferenciação cognitiva. In A. Soares, S. Araújo, \& S. Caires (Orgs.), Avaliação psicológica: formas e contextos Vol. 6 (pp. 352-362). Braga: APPORT.

Bastos, A. (1993). Desenvolvimento humano e intervenção psicológica em contexto educativo. Dissertação de mestrado não publicada. Braga: Universidade do Minho.

Bastos, A. (1998). Desenvolvimento pessoal e mudança em estudantes do ensino superior: Contributos da teoria, investigação e intervenção. Tese de doutoramento não publicada. Braga: Universidade do Minho.

Bastos, A., Faria, C., Silva, C., Carvalho, I., \& Gonçalves, T. (2003). Desenvolvimento cognitivo e dilemas da prática educativa: Contribuições da investigação para a qualidade de ensino. Fases, 2, Artigo 5. Disponível em http://www.ualg.pt/fchs/ceduc/fases/menu2.htm

Bastos, A., Faria, C., Soares, I., Ferreira, J., Medeiros, T., \& Silva, C. (2005). Autoestima, vinculação e desenvolvimento cognitivo em estudantes do ensino superior português: Um estudo exploratório. In A. Bastos, $\mathrm{Na}$ arena dos (des)emparelhamentos construtivos: Contribuições da investigação e da intervenção para o desenvolvimento cognitivo e relacional no ensino superior. Relatório de progresso. Programa de apoio a projectos de pesquisa no domínio educativo (2003-2006). Lisboa: Fundação Calouste Gulbenkian.

Baxter-Magolda, M., \& Porterfield, W. (1985). A new approach to assess intellectual development on the Perry scheme. Journal of College Student Personnel, 26, 343-351.

Berg, C. (1992). Perspectives for viewing intellectual development throughout the life course. In R. Sternberg, \& C. Berg (Eds.), Intellectual development. Cambridge, MA: Cambridge University Press. 
Blackburn, J., \& Papalia, D. (1992). The study of adult cognition from a Piagetian perspective. In R. Sternberg, \& C. Berg (Eds.), Intellectual development. Cambridge, MA: Cambridge University Press.

Blacke, L. (1976). A major of developmental change: A cross-sectional study. Pare presented at annual meeting of the American Psychological Association, Washington, DC.

Bohr, L., Pascarella, E., Nora, A., Zusman, B., Jacobs, M., Desler, M. \& Bulakowski, C. (1994). Cognitive effects of 2-year and 4-year colleges: A preliminary study. Community College Review, 22, 4-11.

Bowen, H. (1977). Investment in learning: The individual and social value of American Higher education. San Francisco: Jossey-Bass.

Cahan, S., \& Cohen, N. (1989). Age versus schooling effects. Child Devellopment, 60, 1239-1249.

Diniz, A. (2001). Crenças, escolhas de carreira e integração universitária. Tese de Doutoramento não publicada. Braga: Instituto de Educação e Psicologia/Universidade do Minho.

Facione, N. (1997). Critical thinking assessment in nursing education programs: An aggregate data analysis. Millbrae, CA: California Academic Press.

Faria, C., \& Bastos, A. (2005). Desenvolvimento epistemológico em estudantes do ensino superior português. In A. Bastos, Na arena dos (des)emparelhamentos construtivos: Contribuições da investigação e da intervenção para o desenvolvimento cognitivo e relacional no ensino superior. Relatório de progresso. Programa de apoio a projectos de pesquisa no domínio educativo (2003-2006). Lisboa: Fundação Calouste Gulbenkian.

Ferreira, I. (2003). Adaptação e desenvolvimento psicossocial dos estudantes do ensino superior: Factores familiares e sociodemográficos. Coimbra: Faculdade de Psicologia e de Ciências da Educação.

Ferreira, J. (1991). As teorias interaccionistas e o desenvolvimento do estudante do ensino superior. Revista Portuguesa de Pedagogia, 25, 91-105.

Ferreira, J. \& Bastos, A. (1995). Inventário de Desenvolvimento Cognitivo de Parker. In L. Almeida, M. Simões, \& M. Gonçalves (Eds.), Provas psicológicas em Portugal, Vol. 1 (pp. 287-307). Braga: APPORT.

Ferreira, J. \& Hood, A. (1990). Para a compreensão do desenvolvimento psicossocial do Estudante Universitário. Revista Portuguesa de Pedagogia, XXIV, 391-406.

Flowers, L. (2000). Cognitive effects of college: Differences between African-American and Caucasian students. Unpublished doctoral dissertation. lowa: University of lowa.

Flowers, L., Osterlind, S., Pascarella, E., \& Pierson, C. (1999). How much do students learn in college? Cross-sectional estimates using the College Basic Academic Subjects Examination. Unpublished manuscript. lowa: University of lowa.

Flowers, L., \& Pascarella, E. (1999). Cognitive effects of college racial composition on African-America students after three years of college. Journal of College Student Development, 40, 669-677. 
Gonçalves, O., \& Cruz, J. (1988). A organização e a implementação de serviços universitários de consulta psicológica e desenvolvimento humano. Revista Portuguesa de Educação, 1(1), 127-145.

Hagedorn, L., Siadat, M. V., Nora, A., \& Pascarella, E. (1997). Factors leading to gains in mathematics during the first year of college: An analysis by gender and ethnicity. Journal of Women and Minorities in Science and Engineering, 3, 185202.

Hart, J., Richards, W., \& Mentkowski, M. (1995). Epistemological development during and after college: Longitudinal growth on the Perry scheme. Paper presented at the meeting of the American Educational Research Association, San Francisco.

Hofer, B., \& Pintrich, P. (1997). Dimensionality and disciplinary differences in personal epistemology. Contemporary Educational Psychology, 25, 378-405.

King, P., \& Kitchener, K. (1994). Developing reflective judgment. San Francisco: JosseyBass.

Kitchener, K., \& King, P. (1981). Reflective judgment: Concepts of justification and their relation to age and education. Journal of Applied Developmental Psychology, 2, 89-116.

Kitchener, K., \& Wood, P. (1987). Development of concepts of justification in Germany university students. International Journal of Behavioral Development, 10, 171185.

Kitchener, K., Wood, P., \& Jensen, L. (1999). Curricular, co-curricular, and institucional influence on real-world problem solving. Paper presented at the meeting of the American Psychological Association, Boston.

Kramer, D. (1983). Post-formal operations? A need for further conceptualization. Human Development, 26, 91-105.

Leitão, L., \& Paixão, M. P. (1999). Contributos para um modelo integrado de orientação escolar e profissional no ensino superior. Psicologia: Teoria, Investigação e Prática, 1, 191-209.

Lencastre, L., Guerra, M., Lemos, M., \& Pereira, D. (2000). Adaptação dos alunos do $1^{\circ}$ ano das licenciaturas da Faculdade de Ciências da Universidade do Porto. In J. Tavares \& R. Santiago (Orgs.), Ensino superior: (In)sucesso académico (pp. 73106). Porto: Porto Editora.

Li, X., Hideki, S., \& Mervin, J. (1996). Perception and reasoning abilities among American, Japanese, and Chinese adolescents. Journal of Adolescent Research, 11(2), 173-193. (ProQuest Document Reproduction Service $\mathrm{N}^{\circ}$ 07435584).

Maia, J., Silva, R., Seabra, A., \& Lopes, V. (2002). A importância do estudo do tracking (estabilidade e previsão) em delineamentos longitudinais: Um estudo aplicado à epidemiologia da actividade física e à performance desportiva-motora. Revista Portuguesa de Ciências do Desporto, 2(4), 41-56.

Marques, J. F., \& Miranda, M. J. (1991). Acesso, ingresso e sucesso no ensino superior. Revista Portuguesa de Pedagogia, II, 155-176.

Martins, E. (1993). Acesso ao ensino superior: Validade preditiva de índices utilizados. Dissertação de mestrado não publicada. Coimbra: Faculdade de Psicologia e de Ciências da Educação, Universidade de Coimbra. 
Martins, E. (2005). O pensamento dos alunos no ensino superior politécnico: um estudo diferencial em função do género, idade e curso. Comunicação apresentada no VII Congresso da Sociedade Portuguesa de Ciências da Educação, Cenários da educação/formação: Novos espaços, culturas e saberes, Castelo Branco.

Martins, E. (2007). Cognição e desempenho no ensino superior. Tese de doutoramento não publicada. Coimbra: Faculdade de Psicologia e de Ciências da Educação, Universidade de Coimbra.

Matos, A. (2004). Televisão e Violência: (Para) Novas Formas de olhar. Tese de doutoramento não publicada. Coimbra: Faculdade de Psicologia e de Ciências da Educação, Universidade de Coimbra.

Medeiros, T., Ferreira, J., Almeida, L., Peixoto, E., Tavares, J., Viveiros, H., \& Morais, F. (2002). Desenvolvimento cognitivo do estudante do ensino superior: Efeito do curso, ano e género. Revista Portuguesa de Pedagogia, 36 (1.2.3), 355-373.

Mendes, F. (2006). Contributos para a Caracterização das Relações entre as Classificações do Ensino Secundário e o Desempenho no Ensino Superior Politécnico. Castelo Branco: Politécnica.

Meyer, P. (1977). Intellectual development: Analysis of religious content. Counseling Psychologist, 6, 47-50.

Mines, R., King, P., Hood, A., \& Wood, P. (1990). Stages of intellectual development and associated critical thinking skills in college students. Journal of College Student Development, 31, 538-547.

Moore, W. (1989). The Learning Environment Preferences: Exploring the construct validity of an objective major of the Perry scheme of intellectual development. Journal of College Student Development, 30, 504-519.

Moore, W. (1991). The measure of intellectual development: An instrument manual. Farmville, VA: Center for the Study of Intellectual Development.

Myerson, J., Rank, M., Raines, F., \& Schnitzler, M. (1998). Race and general cognitive ability: The myth of diminishing returns to education. Psychological Science, 9 , 139-142.

Osterlind, S. (1996). Collegians'scholastic achievement in general education: A national look. Paper presented at the meeting of the American Educational Research Association, New York.

Osterlind, S. (1997). Collegians'scholastic achievement in general education: A national look. Washington DC: George Washington University.

Pascarella, E., Bohr, L., Nora, A., \& Terenzini, P. (1995). Cognitive effects of two-year and four-year colleges: New evidence. Educational Evaluation and Policy Analysis, 17, 83-96.

Pascarela, E., \& Terenzini, P. (1991). How College affects Students: Findings and Insights from Twenty Years of Research. San Francisco: Jossey-Bass.

Pascarella, E., Palmer, B., Moye, M., \& Pierson, C. (2001). Do diversity experiences influence the development of critical thinking? Journal of College Student Development, 42(3), 257-271. (ProQuest Document Reproduction Service $\mathrm{N}^{\circ}$ 08975264). 
Pascarela, E., \& Terenzini, P. (2005). How College affects Students: A Third Decade of Research. San Francisco: Jossey-Bass.

Pearson, F., \& Rodgers, R. (1998). Cognitive and identity development: Gender effects. Initiatives, 58, 17-33.

Pereira, H., \& Medeiros, T. (2005). Concepções de enfermagem e desenvolvimento cognitivo. In T. Medeiros, \& E. Peixoto (Orgs.), Desenvolvimento e Aprendizagem: Do Ensino Secundário ao Ensino Superior (pp. 145-156). Açores: Universidade dos Açores.

Perkins, D. (1985). Postprimary education has little impact on informal reasoning. Journal of Educational Psychology, 77, 562-571.

Perry, W. (1970). Forms of Intellectual and Ethical Development in the College Years. New York: Holt, Rinheart and Winston.

Pestana, M. H., \& Gageiro, J. (2003). Análise de Dados para Ciências Sociais ( $3^{\mathrm{a}}$ ed. Rev.). Lisboa: Edições Sílabo.

Pinheiro, M. R. (2003). Uma Época Especial: Suporte Social e Vivências Académicas na Transição e Adaptação ao Ensino Superior. Tese de doutoramento não publicada. Coimbra: Faculdade de Psicologia e de Ciências da Educação, Universidade de Coimbra.

Pinheiro, M. R., \& Ferreira, J. (2002). O questionário de suporte social: adaptação e validação da versão portuguesa do Social Support Questionnaire (SSQ6). Psychologica, 30, 315-333.

Pinto, H. (2003). Recensão crítica: G.A.B.T. In M. Gonçalves, M. Simões, L. Almeida, \& C. Machado (Coords.), Avaliação Psicológica: Instrumentos Validados para a População Portuguesa, Vol. 1 (pp. 253-301). Coimbra: Quarteto Editora.

Pires, H. (2001). Desenvolvimento e Adaptação Académica em Estudantes Universitários dos PALOP. Tese de doutoramento não publicada. Évora: Universidade de Évora.

Ransdell, S., Hawkins, C., \& Adams, R. (2001). A reaction to the commentaries. International Journal of Educational Research, 35, 427-432.

Ratcliff, J. (1993). What we can learn from coursework patterns about improving the undergraduate curriculum. University Park: Pennsylvania State University, National Center on Postsecondary Teaching, Learning, and Assessment.

Ratcliff, J., \& Jones, E. (1993). Coursework clusters analysis. In T. Banta (Ed.), Making a Difference: Outcomes of a Decade of Assessment in Higher Education (pp. 256-269). San Francisco: Jossey-Bass.

Ratcliff, J., \& Yaeger, P. (1994). What are the coursework patterns most associated with the development of quantitative abilities of college students with low math skills? Paper presented at the meeting of the American Educational Research Association, New Orleans.

Ribeiro, I. (1996). Mudanças no Desempenho e na Estrutura das Aptidões: Contributos para o Estudo da Diferenciação Cognitiva em Jovens. Tese de doutoramento. Braga: Universidade do Minho.

Saucier, B. (1995). Critical thinking skills of baccalaureate nursing students. Journal of Professional Nursing, 11, 351-357. 
Schmidt, J. (1985). Older and wiser? A longitudinal study of the impact of college on intellectual development. Journal of College Student Personnel, 26, 388-394.

Silva, S. (2003). Adaptação Académica, Pessoal e Social do Jovem Adulto ao Ensino Superior: Contributos do Ambiente Familiar e do Autoconceito. Dissertação de mestrado não publicada. Coimbra: Faculdade de Psicologia e de Ciências da Educação, Universidade de Coimbra.

Simões, M. (1994). Investigações no Âmbito da Aferição Nacional do Teste de Matrizes Progressivas de Raven (M.P.C.R.). Tese de doutoramento não publicada. Coimbra: Faculdade de Psicologia e de Ciências da Educação, Universidade de Coimbra.

Snow, R. (1989). Aptitude, instruction, and individual development. International Journal of Educational Research, 13(8), 869-881.

Snow, R. (1994). A person-situation interaction theory of intelligence in outline. In A. Demetriou \& A. Efklides (Eds.), Intelligence, Mind and Reasoning: Structure and Devellopment. Amsterdam: North Holland.

Soares, A. P. (1998). Desenvolvimento Vocacional de Jovens Adultos: a Exploração, a Indecisão e o Ajustamento Vocacional em Estudantes Universitários. Dissertação de Mestrado não publicada. Braga: Instituto de Educação e Psicologia, Universidade do Minho.

Thorndike, R., \& Andrieu-Parker, J. (1992). Growth in knowledge: A two-year longitudinal study of changes in scores on the college basic academic subjects examination. Paper presented at the meeting of the American Educational Research Association, San Francisco.

Underwood, L., Maes, B., Alstadt, L., \& Boivin, M. (1996). Evaluating changes in social attitudes, character traits, and liberal-arts abilities during a four-year program at a Christian college. Research on Christian Higher Education, 3, 115-128.

Whitla, D. (1978). Value added: Measuring the impact of undergraduate education. Cambridge, MA: Harvard University, Office of Instructional Research and Evaluation.

Wood, P. (1997). A secondary analysis of claims regarding the reflective judgment interview: International consistency, sequentiality, and intradivisional differences in ill-structured problem solving. In J. Smart (Ed.), Higher Education: Handbook of Theory and Research, Vol. 12 (pp. 243-312). New York: Agathon.

Wood, P. (2000). Scaling and scoring of an objective measure of epistemic development. Paper presented at the meeting of the American Psychological Association, Washington, DC. 
COGNITIVE DEVELOPMENT, REASONING, AND ACHIEVEMENT IN COLLEGE STUDENTS

\begin{abstract}
In recent years there has been a growing interest in the academic community about the influence of higher education on cognitive development of college students. In addition to the research interest presented to professionals who are interested in studying human development across the life span, in Europe the new challenges of the Bologna Agreement brings to the forefront questions related to the impact of higher education on college students' psychosocial and cognitive development. The purpose of the present research was to longitudinally study the changes in cognitive development, reasoning and achievement, over a period of three years, in a sample of college students, attending a middle size Polytechnic School in Portugal. Results suggest positive changes in reasoning. In terms of cognitive development, results suggest a decrease in values of Relativism and Commitment in Relativism, despite the decrease values in Dualism from first year to the third year, meaning that college students over that period become less dualistic. Suggestions for research and practice are derived from the results of the present study, namely in terms of teaching and learning processes of college students.
\end{abstract}

Keywords

Higher education; Cognitive development; Achievement

PENSÉE, RAISONNEMENT ET PERFORMANCE À L'ENSEIGNEMENT SUPÉRIEUR

\title{
Résumé
}

Cet étude est inséré dans le cadre de l'intérêt croissant sur l'impacte de l'enseignement supérieur sur le développement cognitif de l'étudiant, qui a à l'origine pas seulement la Psychologie du Développement, mais aussi le 
changement du modèle de formation de l'enseignement supérieur, basé sur les défis de la globalisation et assumé dans la Déclaration de Bologne. Comme ça, nous avons suivi un groupe d'étudiants de l'enseignement supérieur polytechnique pendant trois ans en évaluant leur pensée (Perry,1970), raisonnement (contenus numérique et verbal) et performance académique (moyenne de classifications et unités de crédit effectuées). Les résultats mènent à une évolution positive du raisonnement, mais en ce qui concerne la pensée, la situation n'est pas la même, car on assiste à une réduction des niveaux de relativisme et engagement atteints, malgré le fait que la diminution de la pensée dualiste signifie une amélioration cognitive dans ce domaine. De tout ça il y a des implications qui exigent une discussion/ réflexion sur des modèles et des procès d'enseignement/apprentissage dans le cadre de l'évaluation interne de chaque institution.

Mots-clé

Enseignement supérieur; Développement cognitif; Performance

Recebido em Março/2009 Aceite para publicação em Julho/2010

Toda a correspondência relativa a este artigo deve ser enviada para: Emília da Conceição Figueiredo Martins, Escola Superior de Educação do Instituto Politécnico de Viseu, Rua Maximiano Aragão, 3500 Viseu, Portugal. E-mail: emiliamartins@esev.ipv.pt 